\title{
Protocolo para micropropagação de marmeleiro BA29 em meio semissólido
}

\author{
Protocol for micropropagation of quince BA29 in semisolid media
}

\section{Fernanda Grimaldi", Aline Meneguzzi, Gabriela Candido Weber, Daiane Correa, Mayra Juline Gonçalves, Leo Rufato e Aike Anneliese Kretzschmar}

Recebido em 02/02/2015 / Aceito em 20/07/2016

\section{RESUMO}

A micropropagação é uma técnica amplamente conhecida pela sua capacidade de produzir um grande número de plantas em um espaço curto de tempo. É essencial para programas de melhoramento, sendo fundamental o estabelecimento de protocolos de micropropagação para espécies economicamente importantes. O objetivo do presente estudo foi estabelecer um protocolo de micropropagação para o marmeleiro BA29, visando à produção massal de mudas. Explantes de marmeleiro BA29 foram cultivados nos meios de cultura MS e WPM (original e 1/2) combinados com BAP $\left(0 ; 0,5 ; 1 ; 2\right.$ e $\left.4 \mathrm{mg} \mathrm{L}^{-1}\right)$ para a multiplicação in vitro, e cultivados em meio MS com sacarose $\left(15\right.$ e $\left.30 \mathrm{mg} \mathrm{L}^{-1}\right)$ combinados com AIB $\left(0 ; 0,12 ; 0,25 ; 0,50 ; 1,0\right.$ e $\left.2,0 \mathrm{mg} \mathrm{L}^{-1}\right)$ para o enraizamento in vitro. Após 45 dias, o meio de cultura que proporcionou os melhores resultados para crescimento e multiplicação de explantes de BA29 foi o MS original com 2,68 $\mathrm{mg} \mathrm{L}^{-1}$ de BAP e o meio de cultura que proporcionou os melhores resultados para o enraizamento de explantes de BA29 foi MS com 15 $\mathrm{g} \mathrm{L}^{-1}$ de sacarose e $1,25 \mathrm{mg} \mathrm{L}^{-1}$ de AIB.

PALAVRAS-CHAVE: propagação in vitro, Cydonia oblonga, reguladores de crescimento.

\section{ABSTRACT}

Micropropagation is a technique widely known for its ability to produce large numbers of plants in a short period of time. It is essential for breeding programs and to establish micropropagation protocols for economically important species. The aim of this study was to establish a micropropagation protocol for quince BA29, aiming at mass production of plantlets.
The explants of quince BA29 were cultured on MS and WPM media (original and $1 / 2$ ) in combination with $\operatorname{BAP}\left(0,0.5,1,2\right.$ and $\left.4 \mathrm{mg} \mathrm{L}^{-1}\right)$ for the in vitro multiplication and cultured in MS medium with sucrose (15 and $\left.30 \mathrm{mg} . \mathrm{L}^{-1}\right)$ combined with IBA (0, $0.12,0.25,0.50,1.0$ and $\left.2.0 \mathrm{mg} \mathrm{L}^{-1}\right)$ for in vitro rooting. After 45 days, the culture media which provided the best results for growth and multiplication of BA29 explants was the MS original with $2.68 \mathrm{mg} \mathrm{L}^{-1}$ of BAP and the culture media which provided the best results for rooting of BA29 explants was MS with $15 \mathrm{~g} \mathrm{~L}^{-1}$ of sucrose and $1.25 \mathrm{mg} \mathrm{L}^{-1}$ of IBA.

KEYWORDS: in vitro propagation, Cydonia oblonga, growth regulators.

A técnica da micropropagação vem sendo empregada à diversas espécies vegetais, pois possibilita a produção de um grande número de plantas com alta qualidade, homogeneidade e em um curto espaço de tempo. Os principais fatores que influenciam o sucesso da micropropagação são origem do explante, meio nutritivo, luz e temperatura. Existem diversas formulações de meios nutritivos, sua escolha é em geral de acordo com a literatura, onde os compostos orgânicos e os reguladores de crescimento são dependentes da espécie ou explante utilizados (CID \& TEIXEIRA 2010). Apesar das vantagens que a técnica proporciona, seu uso comercial no setor de produção de mudas frutíferas ainda é limitado devido ao alto custo e baixa eficiência que algumas espécies podem apresentar. Considerando que a tendência da fruticultura moderna está voltada aos plantios adensados e ao uso de mudas certificadas se faz necessário o estudo de protocolos de micropropagação para espécies de importância econômica, como o marmeleiro.

Universidade do Estado de Santa Catarina, Lages, SC, Brasil.

*Autor para correspondência <fernandagrimaldi@outlook.com> 
O uso do marmeleiro como porta-enxerto vem sendo estudado em diversas culturas, principalmente na cultura da pereira. Os marmeleiros vêm sendo utilizados de forma crescente por sua versatilidade em desenvolver plantas de pereira anãs e com desenvolvimento precoce (SANSAVINI et al. 2008). Atualmente os marmeleiros estudados como portaenxertos para a pereira são as cultivares EMA, EMC, Adams, BA29, Portugal, Inta 269 e D'Vranja (PASA et al. 2011, PASA et al. 2012, MACHADO et al. 2013). O BA29 se destaca em relação aos demais porta-enxertos de marmeleiro por apresentar compatibilidade com as principais variedades de pereira, alta produtividade e grande calibre de frutos, com controle de vigor da planta (ALONSO et al. 2011).

O marmeleiro BA29, por não ter um protocolo de micropropagação definido, é uma cultivar lenhosa que tem apresentado baixa eficiência durante a multiplicação e enraizamento in vitro, comprometendo a propagação e posterior formação da muda. A formação de brotações e de raízes adventícias em plantas lenhosas é dificultada pelo fato destas plantas possuírem mais camadas de floema e xilema secundários (HARTMANN et al. 2011). Desta maneira o presente estudo teve como objetivo estabelecer um protocolo de micropropagação para o marmeleiro BA29, avaliando a melhor concentração de sais dos meios de culturas MS e WPM combinada com diferentes concentrações de BAP (6-benzilaminopurina) durante a multiplicação in vitro, bem como, avaliando a melhor concentração de sacarose combinada com diferentes concentrações de AIB (ácido indol butírico) durante o enraizamento in vitro de explantes de marmeleiro BA29.

O estudo foi conduzido no Laboratório de Micropropagação Vegetal do Centro de Ciências Agroveterinárias - CAV/UDESC, em Lages, SC. O estabelecimento in vitro do marmeleiro BA29 foi realizado a partir de segmentos nodais provenientes de planta matriz acomodada em casa de vegetação, que recebeu regularmente tratamentos fitossanitários. $\mathrm{O}$ estabelecimento foi feito em tubos de ensaio contendo meio de cultura MS (MURASHIGE \& SKOOG 1962) com $100 \mathrm{mg} \mathrm{L}^{-1}$ de inositol; $30 \mathrm{~g} \mathrm{~L}^{-1} \mathrm{de}$ sacarose; $6 \mathrm{~g} \mathrm{~L}^{-1}$ de ágar; $\mathrm{pH}$ 5,8 80,1 antes da adição do ágar e autoclavagem, sem adição de reguladores de crescimento. Os explantes foram mantidos sob temperatura de $25 \pm 2{ }^{\circ} \mathrm{C}$, primeiramente no escuro por sete dias e após, transferidos para fotoperíodo de 16 horas.
Para a multiplicação in vitro foram utilizados como explantes segmentos caulinares de marmeleiro BA29, de plantas previamente estabelecidas in vitro. Os meios de culturas MS e WPM (LLOYD \& McCOWN 1980) foram testados na concentração original de sais e na concentração de sais reduzidos a metade (MS original, MS1/2, WPM original, $\mathrm{WPM}^{1} 1 / 2$ ). Foram testadas também as seguintes concentrações de BAP: $0 ; 0,5 ; 1 ; 2$ e $4 \mathrm{mg} \mathrm{L}^{-1}$. Todos os meios continham $100 \mathrm{mg} \mathrm{L}^{-1}$ de inositol; $30 \mathrm{~g} \mathrm{~L}^{-1}$ de sacarose; $6 \mathrm{~g} \mathrm{~L}^{-1}$ de ágar e $\mathrm{pH} 5,8 \pm 0,1$ antes da adição do ágar e autoclavagem. Utilizaram-se quatro explantes por frasco, mantidos sob temperatura de $25 \pm 2{ }^{\circ} \mathrm{C}$ e fotoperíodo de 16 horas. O delineamento experimental utilizado foi inteiramente casualizado arranjado em fatorial 4 x 5 (meio x BAP), com cinco repetições por tratamento. Após 45 dias as variáveis analisadas foram: número e comprimento de brotos, número de gemas e número de folhas. Os dados obtidos foram submetidos à análise de variância, empregando o programa SAS 9.1.3. O fator qualitativo (meio de cultura) teve suas médias comparadas através do teste de Duncan, com 5\% de probabilidade de erro, e para o fator quantitativo (concentração de BAP) foi ajustada uma equação de regressão.

Para o enraizamento in vitro foram utilizadas como explantes partes aéreas de marmeleiro BA29 previamente multiplicadas in vitro. Utilizou-se o meio de cultura MS com duas concentrações de sacarose: 15 e $30 \mathrm{~g} \mathrm{~L}^{-1}$. Foram testadas também as seguintes concentrações de AIB: $0 ; 0,12 ; 0,25 ; 0,50 ; 1,0$ e 2,0 $\mathrm{mg} \mathrm{L}^{-1}$. Todos os meios continham $100 \mathrm{mg} \mathrm{L}^{-1}$ de inositol; $6 \mathrm{~g} \mathrm{~L}^{-1}$ de ágar e pH 5,8 $\pm 0,1$ antes da adição do ágar e autoclavagem. Utilizaram-se cinco explantes por frasco, mantidos sob temperatura de $25 \pm 2{ }^{\circ} \mathrm{C}$ e fotoperíodo de 16 horas. O delineamento experimental utilizado foi inteiramente casualizado arranjado em fatorial $2 \times 6$ (sacarose x AIB), com sete repetições por tratamento. Após 45 dias as variáveis analisadas foram: comprimento e número de raiz, comprimento da parte aérea, número de folhas, número de gemas e calo. Os dados obtidos foram submetidos à análise de variância, empregando o programa SAS 9.1.3. O fator qualitativo (sacarose) teve suas médias comparadas através do teste de Duncan, com 5\% de probabilidade de erro, e para o fator quantitativo (concentração de AIB) foi ajustada uma equação de regressão.

No estádio de multiplicação in vitro a análise de variância para as variáveis número e comprimento de brotos foi significativa para ambos os fatores, 
porém sem interação. A variável número de gemas foi significativa apenas para o fator meio de cultura e para a variável número de folhas a análise não foi significativa. O meio MS em sua concentração original de sais obteve as melhores médias para números de brotos e comprimento de brotos, porém, para número de gemas o MS original não diferiu estatisticamente dos meios MS $1 / 2$ e WPM original (Tabela 1). THAKUR \& KANWAR (2008) na multiplicação in vitro de Pyrus pyrifolia não observaram diferença estatística para a comprimento da parte área em relação aos meios de cultura MS e WPM. Porém é importante testar formas reduzidas do meio de cultura, pois a redução de macronutrientes pode ser utilizada como medida para evitar a vitrificação dos explantes. $\mathrm{O}$ maior número de brotos por explante $(7,56$ brotos) foi alcançado com a concentração de $2,68 \mathrm{mg} \mathrm{L}^{-1}$ de BAP (Figura 1). Na multiplicação in vitro de marmeleiro cultivar EMC as concentrações $0 ; 0,7 ; 1,4$ e $2,1 \mathrm{mg} \mathrm{L}^{-1}$ de BAP não influenciaram no número e na altura de brotos, corroborando a necessidade de utilizar maiores concentrações de BAP (SILVA et al. 2009). O BAP é comumente utilizado na faixa de 0,5 a $5,0 \mathrm{mg} \mathrm{L}^{-1}$, sendo o fator genético importante na determinação da concentração necessária da citocinina, portanto a concentração de BAP varia de acordo com a espécie e cultivar estudada (CID \& TEIXEIRA 2010).

Para comprimento de brotos se observou que este diminuiu conforme o aumento da concentração de BAP (Figura 2). Resultados similares foram observados na multiplicação in vitro de porta-enxerto 'Tsukuba 1' (Prunus persica L.) demonstrando que altas concentrações de BAP podem levar à formação de desordens fisiológicas como a redução no crescimento das brotações (RADMANN et al. 2009).

Tabela 1 - Valores médios para números de brotos, comprimento de brotos e números de gemas por explante em meios de cultura com diferentes concentrações de sais para marmeleiro BA29.

Table 1 - Average values for shoot number, shoot length and bud number per explant of quince BA29 in culture media with different salts concentration.

\begin{tabular}{lccc}
\hline Tratamento (Meio) & $\mathrm{N}^{\circ}$ Brotos & Comp. de Brotos & $\mathrm{N}^{\circ}$ Gemas \\
\hline MS original & $6,48 \mathrm{a}$ & $19,19 \mathrm{a}$ & $5,13 \mathrm{a}$ \\
MS $1 / 2$ & $4,81 \mathrm{~b}$ & $16,28 \mathrm{~b}$ & $4,45 \mathrm{ab}$ \\
WPM original & $4,25 \mathrm{~b}$ & $15,63 \mathrm{~b}$ & $4,39 \mathrm{ab}$ \\
$\mathrm{WPM}^{1} / 2$ & $3,30 \mathrm{~b}$ & $12,73 \mathrm{c}$ & $4,16 \mathrm{~b}$ \\
\hline \multicolumn{1}{c}{$\mathrm{CV}(\%)$} & 23,05 & 18,07 & 28,27
\end{tabular}

Dados seguidos de mesma letra na coluna não diferem entre si estatisticamente ao nível de 5\% de significância pelo teste Duncan.
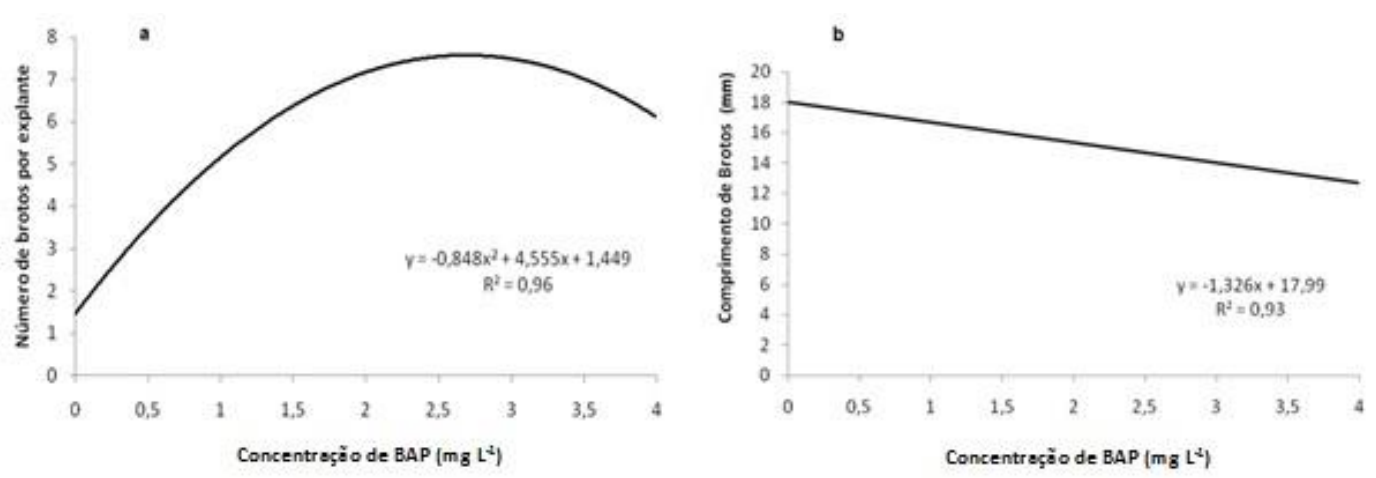

Figura 1 - Número de brotos (a) e comprimento de brotos (b) de explantes de marmeleiro BA29 em função da concentração de BAP.

Figure 1 - Shoot number (a) and shoot length (b) for quince BA29 explants, considering BAP concentration. 
No enraizamento in vitro a análise de variância para as variáveis comprimento de raiz e número de gemas não se mostrou significativa para nenhum dos fatores. Para a variável número de folhas apenas o fator concentração de sacarose foi significativo, onde o maior número médio de folhas foi obtido com 15 $\mathrm{g} \mathrm{L}^{-1}$ de sacarose (Tabela 2). Este resultado poderia ser explicado como um mecanismo de compensação da planta, onde a redução do carboidrato induziu a formação de mais folhas para aumentar a realização da fotossíntese. Porém, de acordo com DEBERGH (1991) nas condições de cultivo in vitro plantas micropropagadas não são fotoautotróficas e sim mixotróficas ou heterotróficas. Para explantes de marmeleiro 'Adams' e 'EMC' o enraizamento in vitro obteve melhores resultados com $15 \mathrm{~g} \mathrm{~L}^{-1}$ de sacarose, e concentrações acima de $30 \mathrm{~g} \mathrm{~L}^{-1}$ apresentaram efeito negativo sobre o enraizamento (ERIG et al. 2004).

Para a variável número de raiz apenas o fator concentração de AIB foi significativo, apresentando um comportamento quadrático ao ajustar uma equação de regressão. O maior número médio de raiz (5,42 raízes) foi obtido com $1,25 \mathrm{mg} \mathrm{L}^{-1}$ de AIB (Figura 2). Concentrações acima deste valor proporcionaram uma diminuição no número de raízes. FISICHELLA \& CINELLI (2000) obtiveram para marmeleiro o maior número médio de raiz com $1 \mathrm{mg} \mathrm{L}^{-1}$ de ANA e ERIG et al. (2004) obtiveram maior enraizamento com $2 \mathrm{mg} \mathrm{L}^{-1}$ de AIB, ANA e AIA. Estes resultados mostram que para cultivares de marmeleiro quantidades de auxina entre 1 e $2 \mathrm{mg} \mathrm{L}^{-1}$ são favoráveis ao enraizamento in vitro. A variável comprimento de parte aérea também se mostrou significativa apenas para o fator concentração de AIB, apresentando um comportamento linear ao ajustar uma equação de regressão (Figura 2). Foi observado que quanto maior a concentração de AIB adicionada ao meio de cultura, maior foi o comprimento da parte aérea, indicando que o AIB contribui para o crescimento da plântula, principalmente porque a auxina está envolvida em diversos processos fisiológicos, sendo responsável não só pela formação de raízes adventícias, mas também pelo alongamento celular (TAIZ \& ZEIGER 2013).

Tabela 2 - Número médio de folhas formadas em explantes de marmeleiro BA29 em função da quantidade de sacarose adicionada ao meio de cultura.

Table 2 - Average number of leaves developed in quince BA29 explants, considering amount of sucrose added to culture media.

\begin{tabular}{cc}
$\begin{array}{c}\text { Sacarose } \\
\left(\mathrm{g} \mathrm{L}^{-1}\right)\end{array}$ & Número médio de Folhas \\
\hline 15 & $6,39 \mathrm{a}$ \\
30 & $4,65 \mathrm{~b}$ \\
\hline $\mathrm{CV}(\%)$ & 35,68 \\
\hline
\end{tabular}

Dados seguidos de mesma letra na coluna não diferem entre si estatisticamente ao nível de 5\% de significância pelo teste Duncan.
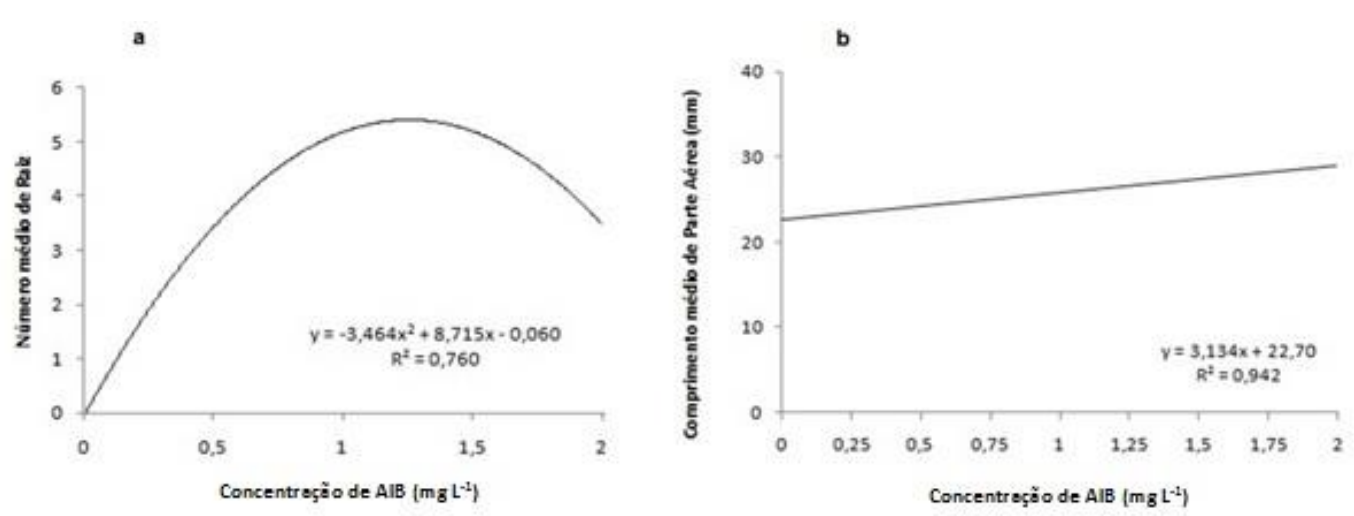

Figura 2 - Número médio de raiz (a) e comprimento de parte aérea (b) de explantes de marmeleiro BA29 em função da concentração de AIB.

Figure 2 - Average root number (a) and shoot length (b) of quince BA29 explants, considering IBA concentration. 
A propagação in vitro do marmeleiro BA29 é bem sucedida quando realizada em meio MS com a concentração de sais originais, alcançando ótimo desenvolvimento de brotos com 2,68 $\mathrm{mg} \mathrm{L}^{-1}$ de BAP durante o estádio de multiplicação e desenvolvimento radicular com $15 \mathrm{~g} \mathrm{~L}^{-1}$ de sacarose e $1,25 \mathrm{mg} \mathrm{L}^{-1} \mathrm{de}$ AIB durante o estádio de enraizamento.

\section{AGRADECIMENTOS}

Os autores agradecem os órgãos CAPES, CNPq e FAPESC pela concessão de bolsas e pelo aporte de recursos financeiros ao Laboratório de Micropropagação Vegetal do $\mathrm{CAV} / \mathrm{UDESC}$.

\section{REFERÊNCIAS}

ALONSO JM et al. 2011. Evaluation of the $\mathrm{OH} \times \mathrm{F}$ selections as an alternative to quince rootstocks for pear: agronomical performance of 'Conference' and 'Doyenné du Comice'. Acta Horticulturae 903:451-455.

CID LPB \& TEIXEIRA JB. 2010. Explante, meio nutritivo, luz e temperatura. In: CID LPB. Cultivo in vitro de plantas. Brasília, DF. 303p.

DEBERGH PC. 1991. Aclimatization techniques of plants from in vitro. Acta Horticulturae 289:291-300.

ERIG AC et al. 2004. Enraizamento in vitro e aclimatização de mudas de marmeleiro cvs. Mc e Adams, utilizadas como porta-enxerto para a pereira. Scientia Agraria 5:61-68.

FISICHELLA M \& CINELLI F. 2000. Effetto del rapporto auxine-citochinine e di inibitori delle auxine e delle gibberelline sulla radicazione e sullo sviluppo in vitro di germogli di cotogno BA29 [Cydonia oblonga Mill.]. Atti V Giornate Scientifiche S.O.I. 2:593-594.

HARTMANN HT et al. 2011. Plant propagation: principles and practices. 8.ed. New Jersey, Prentice Hall. 915p.

LLOYD G \& McCOWN B. 1980. Commercially feasible micropropagation of mountain laurel, Kalmia latifolia, by use of shoot-tip culture. International Plant Propagators' Society 30:420-427.

MACHADO BD et al. 2013. Cultivares e portaenxertos sobre o vigor de plantas de pereira europeias. Ciência Rural 43:1542-1545.

MURASHIGE T \& SKOOG F. 1962. A revised medium for rapid growth and bioassay with tobacco tissue cultures. Physiology Plant 15:473-497.

PASA MS et al. 2011. Hábito de frutificação e produção de pereiras sobre diferentes porta enxertos. Pesquisa Agropecuária Brasileira 46:998-1005.

PASA MS et al. 2012. Desenvolvimento, produtividade e qualidade de peras sobre porta-enxertos de marmeleiro e Pyrus calleryana. Revista Brasileira de Fruticultura 34:873-880.

RADMANN B et al. 2009. Multiplicação in vitro e alongamento das brotações micropropagadas do portaenxerto 'Tsukuba 1' (Prunus persica L.). Revista Brasileira de Fruticultura 31:656-663.

SANSAVINI $S$ et al. 2008. Overview of intensive pear culture: planting density, rootstocks, orchard management, soil-water relations and fruit quality. Acta Horticulturae 800:35-50.

SILVA IMC et al. 2009. Interação BAP x GA3 na multiplicação in vitro do marmeleiro cultivar "MC". XII Congresso Brasileiro de Fisiologia Vegetal. Fortaleza-CE. TAIZ L \& ZEIGER E. 2013. Fisiologia vegetal. 5.ed. Porto Alegre: Artmed. 918p.

THAKUR A \& KANWAR JS. 2008. Micropropagation of 'Wild Pear' Pyrus pyrifolia (Burm F.) Nakai. I. Explant Establishment and Shoot Multiplication. Notulae Botanicae Horti Agrobotanici Cluj-Napoca 36:103-108. 